\title{
Potential Malaysian Medicinal Plants for The Treatment of Alzheimer's Disease
}

Kesevan Rajah Kumaran ${ }^{\mathrm{b}}$, Mohamad Anuar Ahad ${ }^{\mathrm{a}}$, Mira Syahfriena Amir Rawa ${ }^{\mathrm{b}}$, Habibah Wahab ${ }^{\mathrm{b}}$, Zurina Hassan ${ }^{\mathrm{a}^{*}}$

\begin{abstract}
Alzheimer's disease (AD) is a chronic neurodegenerative disease that leads to dementia. AD is characterized by progressive loss of structure and function of neurons that results in neuronal death over time. In the late stage, patients have difficulties to carry out their daily activity as they lose bodily function and needs assistance of a caretaker. The cause of AD is poorly understood and there is no treatment to reverse the progressive loss of neurons in patients until now. Progressive loss of cholinergic neurons and a consequent decline in levels of acetylcholine (ACh) in the brain are the cause of cognitive deterioration in patients suffering AD. Inhibition of cholinesterase (ChE) which are involved in breakdown of $\mathrm{ACh}$ into acetic acid and choline may prevent $\mathrm{ACh}$ level from decreasing. Currently available drugs that act against $\mathrm{ChE}$ are donepezil, rivastigmine and galantamine. These drugs provide symptomatic relief and delays the progress of AD. However, this drugs often produce side effects in consumers. Recently, plants have been given attention as a source of drug to treat neurodegenerative diseases due to its efficiency and less side effect properties. Hence, this review highlights previously and newly discovered potential plants with anti-cholinesterase activity to treat $A D$.
\end{abstract}

Key words: Alzheimer's disease, Malaysian plants, Cholinesterase

\section{Introduction}

Alzheimer's disease (AD) is a leading cause of dementia in elderly people. It is estimated about 15 million people worldwide to be affected with the disease. AD is a progressive neurodegenerative brain disorder and contributes to significant disruption of normal brain structure and physiology. $\mathrm{AD}$ is characterized by a progressive loss of neurons, especially pyramidal cells that mediate higher cognitive functions (Mann, 1996; Norfray et al., 2004). In addition, this disease may disrupt the neural circuits communication related to memory and learning process (Selkoe, 2002). The progression of $\mathrm{AD}$ starts with degeneration of medial temporal lobe, specifically in the entorhinal cortex and hippocampus (Jack et al., 1997).

The pathogenesis of $\mathrm{AD}$ is associated with the cholinergic neurons. Bartus (2000) stated that dysfunction of cholin- ergic neurons in the central nervous system (CNS) contributes significantly to the cognitive functions; it impairs learning and movement associated with ageing and $\mathrm{AD}$. The $\mathrm{ChE}$ is an enzyme involved in cholinergic nerve transmission processes and bound to the cellular membrane of excitable tissues. There are two major enzymes namely acetylcholinesterase (AChE) and butyrylcholinesterase $(\mathrm{BuChE})$. The biological function of these enzymes is to catalyse the hydrolysis of the neurotransmitter known as ACh into acetate and choline, which is a reaction necessary for a cholinergic neuron to return to its resting phase after activation (Holmsted, 1971; Lawson et al., 1987; Barr et al., 1988). Excessive breakdown of ACh may lead to cognitive impairment. $\mathrm{ACh}$ is a neurotransmitter produced from cholinergic neuron and bind to the specific receptors at post-synaptic neuron (Colovic et al., 2013). 
Table 1 represents the list of plants with their percentage of $\mathrm{AChE}$ and $\mathrm{BuChE}$ inhibition activities and IC ${ }_{50}$ value.

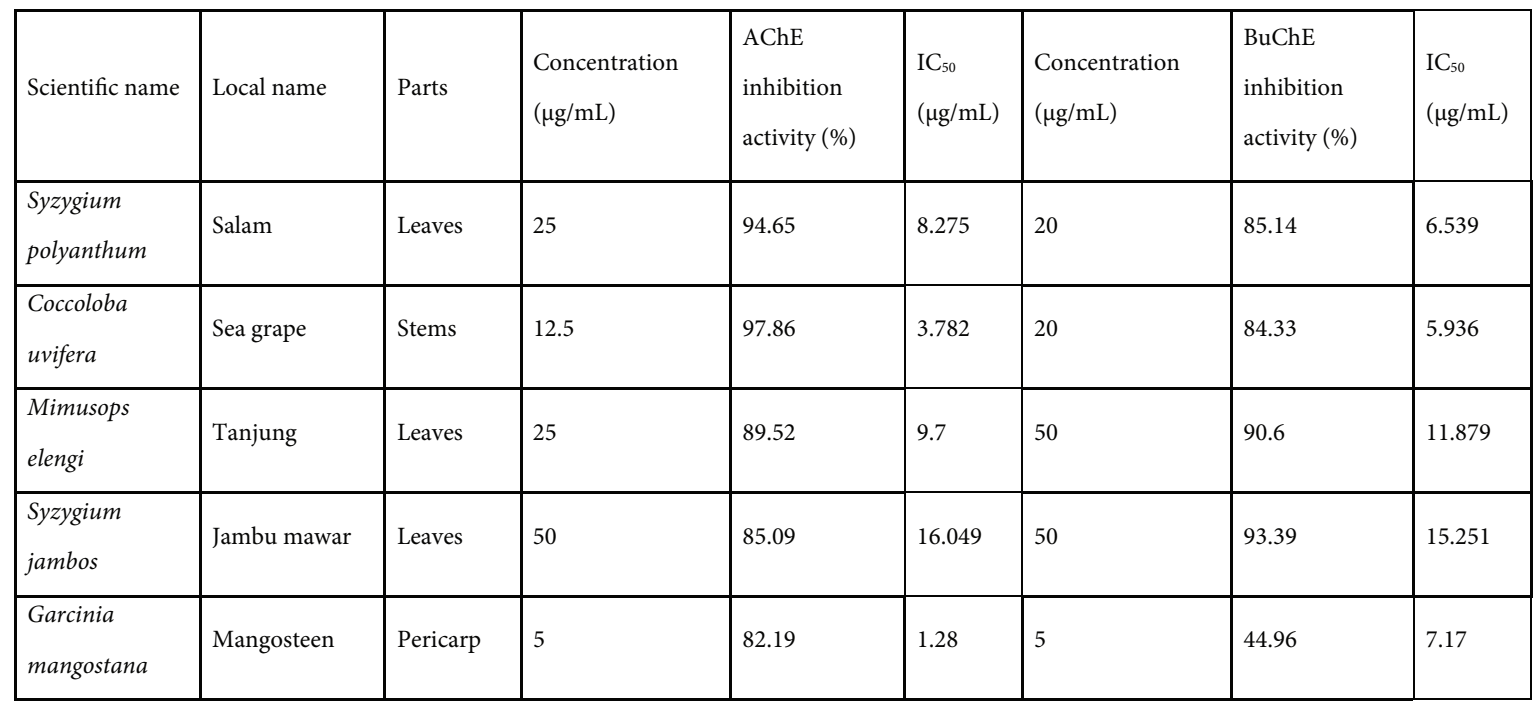

The ChE inhibitor drugs currently used for the treatment of $\mathrm{AD}$ are donepezil, rivastigmine and galantamine (Kaduszkiewicz et al., 2005; Graham et al., 2017). Despite of their effectiveness as inhibitors, they may produce adverse effects such as diarrhoea, vomiting and weight loss (Kaduszkiewicz et al., 2005; Hansen et al., 2008). Hence, current research for the treatment of $\mathrm{AD}$ is focusing on improvement of cognitive impairment through prevention of the ACh breakdown and development of the AChE inhibitors from medicinal plants (Terry et al., 2003).

2. Detection assay. Cholinesterase assay is a method for the determination of both AChE and BuChE activities. Several reported techniques for ChE assay are colorimetric, spectrophotometric, fluorometric, radiometric, or electrochemical techniques. The assay is used to screen the potential drug for AD (Sramek et al., 2000). The most common method for AChE assay is Ellman's method. The principal of this assay is using an alternative substrate known as acetylthiocholine and 5,5'-dithio-bis-2-nitrobenzoic acid (DTNB). The assay reaction results in production of 5-thio-2-nitrobenzoate that exhibits yellow colour due to the shift of electrons to the sulphur atom. The method was established by Ellman and co-workers in the early 1960s (Ellman et al., 1961) and it is utilized until today with several modifications (Phonaka, et al., 2008).

In this review, we have highlighted some of the previously reported and newly discovered plants with anti-cholinesterase activity by performing the method described above with some modification. Briefly, for AChE inhibitory assay, $140 \mu \mathrm{l}$ of $0.1 \mathrm{M}$ sodium phosphate buffer ( $\mathrm{pH} \mathrm{8)}$ was added to each well of 96-well microplate followed by $20 \mu \mathrm{L}$ of the test sample (in DMSO) and $20 \mu \mathrm{L}$ of $0.09 \mathrm{unit} / \mathrm{mL}$ AChE. After 15 minutes of pre-incubation at room temperature, $10 \mu \mathrm{L}$ of 10 mM DTNB was added into each well followed by $10 \mu \mathrm{L}$ of $14 \mathrm{mM}$ acetylthiocholine iodide as substrate. Absorbance of the end product was measured using Multiskan Go at $412 \mathrm{~nm}$ for 30 minutes after initiation of enzymatic reaction. For BuChE inhibitory assay, the same procedure as described above was followed except for the use of enzyme and substrate, which were $\mathrm{BuChE}$ and butyrylthiocholine iodide respectively. Absorbance of the test samples were corrected by subtracting the absorbance of their respective blank (test samples in DMSO with substrate and DTNB, but without enzyme). A set of five concentrations was used to estimate the $\mathrm{IC}_{50}$.

Percentage inhibition was calculated using the following formula:

Percentage inhibition $=$

absorbance of control -absorbance of extract x 100 Absorbance of control

\section{Cholinesterase inhibitory activ-} ities of potential Malaysian medicinal plants

AChE inhibitors are used as a diagnosis modality to prolong the duration of action of the remaining ACh leading to enhancement of cholinergic transmission in AD (Ballard, 2002). Cholinesterase inhibitory activities of some potential Malaysian medicinal plants were listed in Table 1. Garcinia mangostana shows the best AChE inhibitory activity (82\% for AChE) with the lowest concentration $5 \mu$ $\mathrm{g} / \mathrm{mL}$. The definition of $\mathrm{IC}_{50}$ value based on this assay is the concentration of plant extract at which $50 \%$ of enzyme is inhibited. Therefore, the lower the $\mathrm{IC}_{50}$ value of plant extract, the more effective the inhibition activity of plant extract with less off-target effect. Among the plant extract against AChE activity, Garcinia mangostana and Coccoloba uvifera 
extract shows lower $\mathrm{IC}_{50}$ value which are 1.28 and $3.78 \mu \mathrm{g} / \mathrm{mL}$ respectively, followed by Syzygium polyanthum, Mimusops elengi, and Syzygium jambos with $\mathrm{IC}_{50}$ value of $8.27,9.7$ and $16.1 \mu \mathrm{g} / \mathrm{mL}$ respectively. For the BuChE inhibition activity, Coccoloba uvifera, Syzygium polyanthum and Garcinia mangostana shows lower $\mathrm{IC}_{50}$ value of $5.94,6.54$ and $7.17 \mu$ $\mathrm{g} / \mathrm{mL}$ respectively followed by Syzygium jambos with $\mathrm{IC}_{50}$ value of and $15.25 \mu \mathrm{g} / \mathrm{mL}$ respectively. The results obtained indicate all plant extracts possesses good AChE and BuChE inhibition activities and have potential to be used as medicine to treat AD.

\section{Botanical origin and pharma- cological properties of potential Malaysian medicinal plants}

4.1 Syzygium polyanthum. Syzygium polyanthum or Salam belongs to family member of Myrtaceae that grows in temperate, tropical and subtropical regions of the world. The leaves of this plant are commonly used in cooking to enhance pleasing aroma of local dishes (Shanmugapriya et al., 2012). Besides using as a spice in cooking, Salam leaves have been used traditionally as medicine or therapeutic agents against ulcer, hypertension, hyperuricemia, diarrheal, gastritis, skin diseases and inflammation. In Indonesia, decoction of Salam leaves is used as one of the ingredients in "Jamu" that are prepared specifically to treat diabetes. An in vitro study conducted by Widyawati et al. (2015) revealed that the methanol extract of Salam leaves inhibited the absorption of glucose from the intestine and augment uptake of glucose in muscle tissues. Methanol extract of Salam leaves is able to reduce microbial population in chicken and shrimp with good sensory acceptability, hence may have the potential to be developed as a natural food sanitizer in future (Ram Li et al., 2017). So far there is only one study reported that Salam leaves extract has lower $\mathrm{IC}_{50}$ value for AChE inhibition when compared to other plant in Syzygium genus like S. cumini leave and S. aromaticum bud extracts (Darusman et al., 2013). Our finding further supports the AChE inhibition activity of these plant leaves. In spite of that, there are no studies performed on the BuChE inhibition activity previously. Further studies are needed to reveal the neuroprotective properties of this plant.

4.2 Coccoloba uvifera. Coccoloba uvifera or sea grape belongs to the buckwheat family, Polygonaceae. Sea grape is a sprawling evergreen shrub or small tree that can grow up to 8 meters. This tree is found in coastal beaches throughout tropical America and the Caribbean, including southern Florida, the Bahamas, Barbados and Bermuda. This plant produces green fruit in large grape-like clusters. The fruits gradually change colour to purplish when ripens. Each fruit contains a large pit that constitutes most of the volume of the fruit (Campos, Ruiz, Chel-Guerrero \& Ancona, 2015). Sea grape leaves were found to reduce blood glucose level and acts as an antioxidant (Povi et al., 2015). The fruit is a good source of nutrients and shows in vitro antioxidant properties comparable to those of conventional fruits. The antioxidant effects appeared to be due to the phytochemical contents like polyphenols, flavonoids, anthocyanins and ascorbic acid (Campos, Ruiz, Chel-Guerrero \& Ancona, 2015). So far, there are no studies performed on neuroprotective effect of this plant. Hence, this is the first report to reveal the AChE and BuChE inhibition activities of this plant. This underutilized plant may provide tremendous health benefits to human. Therefore, more studies are needed to reveal the therapeutic properties along with toxicity of this plant.

4.3 Mimusops elengi. Mimusops elengi or locally known as Tanjung is a 30 -feet-tall tree, with a wavy and dull green leaf, greyish brown fissured bark, oblong berry fruit and flowers with creamy fragrant found in tropical and subtropical regions (Amir et al., 2013). The bark extracts have been proven to have anti-anxiety in mice, anti-urolithiatic in rats, anti-ulcer, anti-hyperlipidemic, anti-convulsant, wound healing effect, analgesic, antipyretic and anti-inflammatory activity. $\quad \beta$-amyrincaprylate and betulinic acids found in Tanjung bark contribute to the anti-inflammatory action and anti-HIV activity respectively (Prasad et al., 2012). The leaves extract was found to have anti-helminthics activity against Pheretima posthuma, anti-atherosclerotic, anti-diabetic and diuretic activities. Spinasterol in leaves extract has anti-bacterial and anti-inflammatary activity (Amir et al., 2013). Although previously, there are no studies conducted on anti-BuChE activity of this plant, there are quite several studies conducted to investigate the anti-AChE potential and other neuroprotective effect of this plant. An in vitro study conducted by Sainiara et al. (2015) revealed that methanolic extract from flower and leaves of Tanjung can inhibit AChE. Moreover, the inhibition activity of the flower was found to be higher compared to the leaves. Based on in vivo studies, treatment with hydroalcoholic Tanjung flower extract in rats with colchicine-induced AD shows improvement in memory and cognitive function and reduced $\mathrm{AChE}$ 
activity were found in the brain of treated rats (Chitra et al., 2016). Ethanolic extract of Tanjung flower up to $2 \mathrm{~g} / \mathrm{kg}$ of body weight does not show any toxic effect (Hadaginhal et al., 2010). Besides flower extract, methanol extract of Tanjung leaves were found to improve memory in mice with amnesia due to normal ageing and administration of scopolamine and diazepam, which suggest that Tanjung leaves may have the potential to be used as a memory invigorating agent. Treatment of 100 and $200 \mathrm{mg} / \mathrm{kg}$ of Tanjung bark extract is able to decrease whole brain AChE activity significantly and improve amnesia induced by diazepam and scopolamine in both young and old mice (Josji \& Parle, 2012). This study revealed that the leaves, flowers and bark of Tanjung plant could have a memory improving potential which can be used as supplements for $\mathrm{AD}$ patients to reverse their memory decline.

\subsection{Syzygium jambos. Syzygi-} um jambos or also known as "rose apple" is a large bush or small to medium sized woody fruit tree, originated from Southeast Asia, but now widely grown in the tropics (Nawwar et al., 2016). All parts of the plant are reported to have medicinal values. In China, the leaves of rose apple are consumed as herbal tea. The leaves decoction is used as diuretic and to treat rheumatism, sore eyes (Li et al., 2015) and diabetes. The leaves extract was also proven to have anti-bacterial activity against Salmonella typhi (Murugan et al., 2011) and anti-viral activity against vesicular somatitis virus, herpes simplex type 1 and type 2 (Athikomkulchai et al., 2008). The fruits were used as diuretic and tonic for brain and liver. The flowers were believed to reduce fever and the seeds were used to treat diarrhoea, dysentery and catarrh. The bark decoction is administered to relieve asthma and bronchitis. Rose apple extract also had an analgesic effect on muscle hyperalgesia and inflammatory cutaneous pain with an efficacy higher than that of diclofenac (known as an anti-inflammatory drug). It also possesses long-lasting analgesia effect for thermal cutaneous pain with onset time and efficacy comparable to that of morphine (potent opioid analgesic) without involving opioid receptor (Avila-Pena et al., 2007). To date, there is no in vitro or in vivo studies that reveals the potential of this plant as neuroprotective agent to treat neurodegenerative diseases. This is the first report on the $\mathrm{AChE}$ and $\mathrm{BuChE}$ inhibition activity of this plant. This plant has the potential to be used in improving cognitive and memory as myricetin present in this plant leaves has been reported to significantly reverse cognitive deficits in scopolamine-induced mice by inhibiting AChE activity (Wang et al., 2017).

\subsection{Garcinia mangostana. The} tropical plant, Garcinia mangostana or locally known as mangosteen belongs to Guttiferae family. This plant can be found in the Asian region for instance Malaysia, Myanmar, Thailand, Philippines, Sri Lanka and India. Several in vitro and in vivo studies have shown a wide range of pharmacologic actions of mangosteen, including anti-malarial, anti-carcinogenic, anti-bacterial, anti-fungal and anti-atherogenic activities along with neuroprotective properties in AD (Obolskiy et al., 2009). A randomized, double blinded, placebo-controlled study using 59 healthy human subjects with age ranging between 40 to 60 years old, pointed out that the intake of mangosteen product significantly enhances immunity and improves self-appraisal on subject's overall health condition (Tang et al., 2009). Mangosteen pericarp extract with concentration of $100 \mu \mathrm{g} / \mathrm{mL}$ showed $51.93 \%$ inhibition activity against AChE meanwhile the positive control, eserine hemisulphate showed 93.87\% inhibitory activity at 0.25 $\mu \mathrm{g} / \mathrm{mL}$. The $\mathrm{IC}_{50}$ values of mangosteen and eserine hemisulphate were 42.05 and $0.020 \mu \mathrm{g} / \mathrm{mL}$ respectively. This inhibitory effect of mangosteen pericarp extract proposed that mangosteen has potential application in the treatment of AD (Raghavendra et al., 2011). Huang et al. (2014) found that treatment with pericarp extract significantly decreases the cell mortality and increases the Brain-derived neurotrophic factor (BDNF) level in vitro. After 8 months of dietary supplementation of mangosteen pericarp diet $(5000 \mathrm{ppm})$, a significant improvement on cognitive impairment associated with anti-inflammation, increasing BDNF level and decreasing p-tau were observed in older B6 mice. Besides that, administration of this diet supplement to triple Transgenic Alzheimer's disease $(3 \times \mathrm{Tg}-\mathrm{AD})$ mice, exerted neuroprotective, anti-oxidative, anti-inflammatory effects and reduces the amyloid- $\beta$ (A $\beta)$ deposition along with p-tau (S202/S262) levels in the hippocampus, which might further attenuate the deficit in spatial memory retrieval. Sattayasai et al., (2013) found that mangosteen extract reduces reactive oxygen species level and caspase-3 activity as well as improves memory in scopolamine induced mice.

The pericarps of mangosteen are rich in xanthones. Among the xanthones, a-mangostin has received much attention due to its high antioxidant properties (Tjahjani et al., 2014). a-mangostin was identified as an 
an AChE selective inhibitor as this compound significantly inhibits more AChE as compared to BuChE. On the other hand, $\gamma$-mangostin is classified as a dual inhibitor as it shows almost equal selectivity towards both enzymes. Furthermore, Wang et al. (2012) discovered the potential of $\alpha$-mangostin to reduce $A$ $\beta$ oligomers induced neurotoxicity in vitro. Molecular docking and dynamics simulations were utilized to demonstrate binding of $\alpha$-mangostin to $A \beta$ and stabilize a-helical conformation. It was found that $\alpha$-mangostin could detach $A \beta(1-40)$ and $A \beta$ (1-42) oligomers directly via blotting with oligomer specific antibodies. The disruption of pre-formed fibrils as well as hindering of fibril formation were observed in ThioflavinT fluorescence assay and electron microscopy imaging.

Besides possessing good health benefits, a-mangostin shows low cytotoxic effects against normal liver cells (WRL-68) in vitro. Acute treatment of $\alpha$-mangostin via oral gavage at single doses of 100,500 , and $1000 \mathrm{mg} / \mathrm{kg}$ does not produce any toxicity in Institute of Cancer research (ICR) mice, a commonly used outbred mice. There were no adverse effects observed on body weight, organ weight, serum biochemistry, histopathology and oxidative stress biomarkers in a-mangostin treated mice (Ibrahim et al., 2015). Additionally, oral administration of $a$-mangostin did not produce any toxic effect in rats till the dose $1250 \mathrm{mg} / \mathrm{kg}$ body weight (Kumar et al., 2016). Due to their high safety and results from the above studies revealed that mangosteen pericarp extract might offer a promising supplementary diet to attenuate cognitive dysfunction in
AD.

5. Conclusion. In conclusion, there is still no cure for $\mathrm{AD}$ until today. The medicines available in the market will only provide symptomatic reliefs for a short period of time but the degeneration of neurons is continuous gradually. In recent years, medicinal plant-derived natural compounds have received extensive attention as major sources of new therapeutic agents for treating neurodegenerative diseases or neurological disorders. The drugs prepared from plants are considered moderate in efficacy, less toxic and relatively low cost as compared to commonly used pharmaceutical drugs. Hence, utilization of this abundantly available natural resources will provide beneficial health effect on ageing population that are prone to $\mathrm{AD}$.

\section{Acknowledgement}

Financial support was received from RU TOP-DOWN for the project entitle Catalogue of USM-RIKEN Natural Product (CURINaP) Library for the Discovery of Bioactive Molecules on Ageing and Ageing Related Diseases (1001/PFARMASI/870031).

\section{References}

Amir, F., Wong, K., Eldeen, I., Asmawi, M., \& Osman, H. (2013). Evaluation of Biological Activities of Extracts and Chemical Constituents of Mimusops elengi. Tropical Journal of Pharmaceutical Research, 12(4). 591-596.

Athikomkulchai, S., Lipipun, V., Leelawittayanont, T., Khanboon, A., \& Ruangrungsi, N. (2008). Anti-herpes Simplex Virus Activity of Syzygium jambos. Journal of Health Research, 2008(22), 49-51.

Avila-Pena, D., Pena, N., Quintero, L., \& Suarez-Roca, H. (2007). Antinociceptive Activity of Syzygium jambos Leaves Extract on Rats. Journal of Ethnopharmacology, 112(2), 380-385.

Ballard, C.G. (2002). Advances in the treatment of Alzheimer's disease: Benefits of dual cholinesterase inhibition. European Neurology, 47, 67-70.

Barr, R. D., Koekebakker, M. \& Lawson, A. A. (1988). Acetylcholinesterase in the Human Erythron. II. Biochemical assay, American Journal of Hematology, 28, 260.

Bartus, R. T. (2000). On Neurodegenerative Diseases, Models, and Treatment Strategies: Lessons Learned and Lessons Forgotten a Generation Following the Cholinergic Hypothesis. Experimental Neurology, 163, 495-529.

Campos, M. R., Ruiz, J. R., Chel-Guerrero, L., \& Ancona, D. B. (2015). Coccoloba uvifera (L.) (Polygonaceae) Fruit: Phytochemical Screening and Potential Antioxidant Activity. Journal of Chemistry, 2015, 1-9.

Chitra, V., Tamilanban, T., Manasa, K., \& Chitra, K. (2016). Cognitive and Anti-oxidant Property of Mimusops elengi Linn. in the Experimental Model of Alzheimer's Disease in Rats. International Journal of PharmTech Research, 9(3), 311-319.

Colovic, M. B., Krstic, D. Z., Lazarevic-Pasti, T. D., Bondzic, A. M. \& Vasic, V. M. (2013). Acetylcholinesterase Inhibitors: Pharmacology and Toxicology. Current Neuropharmocology,11(3), 315-335.

Darusman, L. K., Wahyuni, W. T., \& Alwi, F. (2013). Acetylcholinesterase Inhibition and Antioxidant Activity of Syzygium cumini, S. aromaticum and S. polyanthum from Indonesia. Journal of Biological Sciences, 13(5), 412-416.

Ellman, G.L., Courtney, D. K., Andreas, V. \& Featherstone, R. M. (1961). A New and Rapid Colorimetric Determination of Acetylcholinesterase Activity. Biochemical Pharmacology, 7, 88-95.

Graham, W. V., Bonito-Oliva, A. \& Sakmar, T. P., (2017). Update on Alzheimer's Disease Therapy and Prevention Strategies. Annual Review of Medicine, 68, 413-430

Hadaginhal, R. V., Tikare, V. P., Patil, K. S., Bhanushali, M. D., Desai, N. S., \& Karigar, A. (2010). Evaluation of Congnitive Enhancing Activity of Mimusops elengi linn on Albino Rats. International Journal of Research in Ayurveda \& Pharmacy, 1(2), 484-492 
Hansen, R. A., Gartlehner, G., Webb, A. P., Morgan, L. C., Moore, C. G. \& Jonas, D. E. (2008). Efficacy and Safety of Donepezil, Galantamine, and Rivastigmine for the Treatment of Alzheimer's Disease: A Systematic Review and Meta-analysis. Clinical Interventions in Aging, 3(2), 211-225.

Huang, H., Chen, W., Hsieh, R., \& Hsieh-Li, H. M. (2014). Multifunctional Effects of Mangosteen Pericarp on Cognition in C57BL/6J and Triple Transgenic Alzheimer's Mice. Evidence-Based Complementary and Alternative Medicine, 2014, 1-18.

Ibrahim, M. Y., Hashim, N. M., Mohan, S., Abdulla, M. A., Abdelwahab, S. I., Arbab, I. A., .. Ishag, O. E. (2015). a-Mangostin from Cratoxylum arborescens: $\mathrm{An}$ in vitro and in vivo Toxicological Evaluation. Arabian Journal of Chemistry, 8(1), 129-137.

Jack, C. R., Petersen, R. C., Xu, Y. C., Waring, S. C., O'Brien, P.C., \& Tangalos, E. G. (1997). Medial Temporal Atrophy on MRI in Normal Aging and Very Mild Alzheimer's Disease. Neurology, 49, 786-794.

Kaduszkiewicz, H., Zimmermann, T., Beck-Bornholdt, H. P. \& Bussche, H. V. D. (2005). Cholinesterase inhibitors for patients with Alzheimer's disease: Systematic review of randomised clinical trials. BMJ, 331(321).

Kumar, V., Bhatt, P. C., Kaithwas, G., Rashid, M., Al-Abbasi, F., Khan, J. A., . . Verma, A. (2016). a-Mangostin Mediated Pharmacological Modulation of Hepatic Carbohydrate Metabolism in Diabetes Induced Wistar Rat. Beni-Suef University Journal of Basic and Applied Sciences, 5(3), 255-276.

Lawson, A. A. \& Barr, R. D. (1987). Acetylcholinesterase in red blood cells. American Journal of Hematology, 26, 101.

Li, G., Zhang, Y., Wu, P., Chen, N., Wu, Z., Yang, L., . . . Li, Y. (2015). New Phloroglucinol Derivatives from the Fruit Tree Syzygium jambos and Their Cytotoxic and Antioxidant Activities. Journal of Agricultural and Food Chemistry, 63(47), 10257-10262.

Mann, D. M. (1996). Pyramidal nerve cell loss in Alzheimer's disease. Neurodegeneration, 5, 423-427.

Murugan, S., Uma Devi, P., Parameshwari, K. N., \& Mani, K, R. (2011). Antimicrobial Activity of Syzygium jambos Against Selected Human Pathogens. International Journal of Pharmacy and Pharmaceutical Sciences, 2011(3), 44-47.

Nawwar, M., Hashem, A., Hussein, S., Swilam,
N., Becker, A., Haertel, B., ... Linscheid, M. (2016). Phenolic Profiling of an Extract from Eugenia Jambos L. (Alston): The Structure of Three Flavonoid Glycosides-Antioxidant and Cytotoxic Activities. Die Pharmazie-An International Journal of Pharmaceutical Sciences, 71, 162-168.

Norfray, J. F. \& Provenzale, J. M. (2004). Alzheimer's Disease: Neuropathologic Findings and Recent Advances in Imaging. American Journal of Roentgenology, 182: 3-13.

Obolskiy, D., Pischel, I., Siriwatanametanon, N., Heinrich, M. (2009). Garcinia mangostana L.: A Phytochemical and Pharmacological Review. Phytotherapy Research, 23(8), 1047-1065.

Povi, L., Batomayena, B., Hode, T. A., Kwashie, E., Kodjo, A., \& Messanvi, G. (2015). Phytochemical Screening, Antioxidant and Hypoglycemic Activity of Coccoloba Uvifera Leaves and Waltheria Indica Roots Extracts. International Journal of Pharmacy and

Pharmaceutical Sciences, 7(5), 279-283.

Prasad, V. K., Kavita, N. Y., Ramesh, S. D., Rakesh, S. S., \& Manohar, J. P. (2012). Mimusops elengi: A Review on Ethnobotany, Phytochemical and Pharmacological Profile. Journal of Pharmacognosy and Phytochemistry, 1(3), 64-74.

Raghavendra, H., Kumar, S. P., Kekuda, T. P., R., Ejeta, E., Mulatu, K., . . Anilakumar, K. (2011). Extraction and Evaluation of a-Mangostin for its Antioxidant and Acetylcholinesterase Inhibitory Activity. Journal of Biologically Active Products from Nature, 1(5\&6), 314-324.

RamLi, S., Radu, S., Shaari, K., \& Rukayadi, Y. (2017). Antibacterial Activity of Ethanolic Extract of Syzygium polyanthum L. (Salam) Leaves against Foodborne Pathogens and Application as Food Sanitizer. BioMed Research International, 2017, $1-13$.

Sainiara,B., Jayashree, A., Archana, B., \& Bratati, D. (2015). Chemical Composition and in vitro Study for Analysis of Potential Neuroprotective and Antidiabetic Activity in Mimusops elengi L. International Journal of Pharmacognosy and Phytochemical Research, 7(4), 701- 706.

Sattayasai, J., Chaonapan, P., Arkaravichie, T., Soi-Ampornkul, R., Junnu, S., Charoensilp, P. Moongkarndi, P. (2013). Protective Effects of Mangosteen Extract on $\mathrm{H} 2 \mathrm{O} 2$-Induced Cytotoxicity in SK-N-SH Cells and Scopolamine-Induced Memory Impairment in Mice. PLoS ONE, 8(12). 1-13.

Selkoe, D. J. (2002). Alzheimer's disease is a synaptic failure. Science, 298, 89-91.

Shanmugapriya, P., Roziahanim, M., Piaru, S. P., Cai, L. W., \& Surash, R. (2012). Potential Antiradical
Activity and Cytotoxicity Assessment of Ziziphus mauritiana and Syzygium polyanthum. International Journal of Pharmacology, 8(6), 535-541.

Sramek, J. J., Cutler, N. R. (2000). RBC Cholinesterase Ihibition: A Useful Surrogate Marker for Cholinesterase Inhibitor Activity in Alzheimer Disease Therapy? Alzheimer Disease and

Associated Disorder, 14, 216-227. Alzheimer Disease and Associated Disorders

Tang, Y., Li, P., Kondo, M., Ji, H., Kou, Y., \& Ou, B. (2009). Effect of $a$-Mangosteen Dietary Supplement on Human Immune Function: A Randomized, Double-Blind, Placebo-Controlled Trial. Journal of Medicinal Food, 12(4), 755-763.

Terry, A. V. \& Buccafusco, J. J. (2003). The Cholinergic Hypothesis of Age and Alzheimer's Disease-Related Cognitive Deficits: Recent Challenges and Their Implications for Novel Drug Development. Journal of Pharmacology and Experimental Therapeutics, 306(3), 821-827.

Tjahjani, S., Widowati, W., Khiong, K., Suhendra, A., \& Tjokropranoto, R. (2014). Antioxidant Properties of Garcinia Mangostana L. (Mangosteen) Rind. Procedia Chemistry, 13, 198-203.

Wang, B., Zhong, Y., Gao, C., \& Li, J. (2017). Myricetin Ameliorates Scopolamine-Induced Memory Impairment in Mice via Inhibiting Acetylcholinesterase and Down-Regulating Brain Iron. Biochemical and Biophysical Research Communications, 490(2), 336-342.

Wang, M., Zhang, K., Gu, Q., Bi, X., \& Wang, J. (2017). Pharmacology of Mangostins and Their Derivatives: A Comprehensive Review. Chinese Journal of Natural Medicines, 15(2), 81-93.

Widyawati, T., Yusoff, N., Asmawi, M., \& Ahmad, M. (2015). Antihyperglycemic Effect of Methanol Extract of Syzygium polyanthum (Wight.) Leaf in Streptozotocin-Induced Diabetic Rats. Nutrients, 7(9), 7764-7780

\section{About the author}

Our research focuses on discovering potential bioactive compounds from plants found in Malaysia against cholinesterase enzymes for the treatment of Alzheimer's disease. Initially, we have screened 300 plant extracts using in vitro enzymatic assay and discovered a number of plant extracts with high $\mathrm{AChE}$ and BuChE inhibition activities. Currently, the selected plant extracts are being tested in vivo to determine the effectiveness of this plant extracts in improving memory and inhibiting $\mathrm{AChE}$ and BuChE activities in rat's brain. We also working on isolation and purification of bioactive compounds against AChE and BuChE activities based on bioassay guidance. We hope our research findings could contribute to the development of more effective anti-cholineterase drugs with less side effects to improve memory in ageing population. 